\title{
A new theoretical method for predicating the part-load performance of natural
}

\section{draft dry cooling towers}

\author{
Huan $\mathrm{Ma}^{1}$, Fengqi $\mathrm{Si}^{1}{ }^{1 *}$, YuKong ${ }^{1}$, Kangping $\mathrm{Zhu}^{2}$, Wensheng $\mathrm{Yan}^{2}$ \\ ${ }^{1}$ Key Laboratory of Energy Thermal Conversion and Control of Ministry of \\ Education, School of Energy and Environment, Southeast University, Nanjing, \\ 210096, P.R. China \\ ${ }^{2}$ CPI Shentou Power Generation Co.,Ltd., Shuozhou, 036800, P.R. China
}

Corresponding author: Prof. Dr. Fengqi Si.

Address:School of Energy \& Environment, SouthEast University, No.2 Sipailou

Road, Nanjing, 210096, China.

Tel: +862583790579 .

E-mail address: $\underline{\text { qqsi@seu.edu.cn }}$ 
1 Abstract:

2 A newtheoretical modelis proposedto predict thermal performance of natural draft

3 dry cooling tower (NDDCT) under various ambient conditions. When evaluating the

4 effect of ambient temperature, heat rejection of the NDDCT is converted to the form

5 that is proportional to the power function of initial temperature difference of the tower,

6 using the theory of similar triangles. Heat rejection of the NDDCT under windy

7 condition is simply calculated based on the outlet air velocity obtained bya proposed

8 algorithm. Although thistheoretical model is inappropriate atcrosswind velocity higher

9 than the critical wind velocity, it's still meaningful for thermal performance prediction

10 of the NDDCT, because thiscritical wind velocityis usually large and uncommon in

11 the practical operation of the tower.Testing work for a $600 \mathrm{MW}_{\text {thand }}$ other two

12 NDDCTs is conducted using this theoretical model flexibly, and the predictions agree

13 well with practical measurement data or results available in the existing literatures. In

14 addition, analysis of the $600 \mathrm{MW}_{\text {th }}$ NDDCT shows that under a lager initial

15 temperature difference, the tower has larger resistance to crosswindand cooling

16 efficiency declines more slowly, Moreover, heat rejection of the tower increases more

17 rapidly with initial temperature difference under a smaller crosswind velocity.

18 Key words:thermal performance; natural draft dry cooling tower; theoreticalmodel;

19 ambient temperature; crosswind;initial temperature difference 


\section{1. Introduction}

2 Natural draft dry cooling tower(NDDCT) including heat exchanger which is

3 arranged vertically or horizontally at the bottom of the tower, is an energy-efficient

4 cooling equipment in power plants. Thanks to the water-saving advantage, it has been

5 widely used in the regions with rich coaland lack of water [1, 2]. Air movement in or

6 around the NDDCT is dependent on density difference between entering cold air and

7 internal warm air[3]. When passing across heat exchanger, the entering air will be

8 heated by hot circulating water inside the heatexchanger bundles by convective heat

9 transfer. Then, buoyancy originatingfrom density difference between entering cold air

10 and internalwarm air drives upwelling flows inside the tower and draws fresh air in at

11 the same time. As a consequence,thermal performance of the NDDCT is high

12 sensitive to ambient conditions[3-6].

13 To figure out performance variation caused by ambient condition, there are two

14 main kinds of methods, one is experimental research, and the other is numerical

15 research, sometimes verified by experiment under certain conditions. As for

16 experimental research,Ardekani et al. [7] experimentally evaluated thermal

17 performance of the cooling tower under actual wind conditions prevailing around the

18 tower. These measurements showed that the tower front cooling sectors experience

19 better airflow distribution comparedto sectors parallel to wind direction, which

20 improves their thermal performance by about $20 \%$ compared to still-air conditions.

21 Wind tangential velocity at corner sector is four times the velocity at the

22 referencepoint, decreasing air pressure and tower suction. Weiet al.[8] investigated the 
1 unfavorable effect of wind on the performance of drycooling towerswith full-scale

2 and wind-tunnel experiments, and then explainedthree reasonsfordeterioration of

3 cooling efficiency reduced by wind, i.e., anunfavorable pressure distribution at the

4 tower entrance, breaking of theplume rising at the tower exit, and cold inflow of cool

5 air induced by leading edge separation. There is no doubt that full-scale experiment is

6 the most direct way to figure out thermal performance of the tower. However, the

7 NDDCT is a complex large-scale object involving fluid and heat flows, and it takes a

8 lot of time and resources for one experiment. Moreover, real-world environment is

9 uncontrollable, changing stochastically. All these reduce the reliability and practicality

10 of full-scale experiment. As for wind-tunnel experiment, it can't well predict the real

11 thermohydraulic behavior of the tower, owing to aset of restrictions and doubtful

12 simplifications applied in dimensional analysis and the experience procedure[9].

13 As for numerical research, with the development of turbulence theory and

14 computational technology, it has been more and more applied in the field of

15 NDDCT.Su et al.[10]numerically investigated fluid flow and temperature distribution

16 in and around a dry cooling tower. The study indicated thatthe wind-caused tangential

17 airflow at external sides ofthe heat exchanger is the major cause for the

18 coolingefficiency reduction, and the numerical results have a satisfied agreement with

19 full-scale measurement data. Du Preez et al. [11] carried out extensive experimental

20 and numerical research on the influence of the particular heat exchanger arrangement

21 on the performance of the tower in windy conditions. Practical suggestions

22 concerning the arrangement of heat exchanger and wind-break walls were 
1 recommended to reduce the adverse effect of crosswind on the dry cooling tower

2 performance. Al-Waked et al. [3, 5]investigated the effects of crosswind and ambient

3 temperature on thermal performance of an NDDCT with a three-dimensional CFD

4 model which was verified by experimental results. To improve thermal performance

5 of the tower under windy conditions, the shape, dimensions, location and material of

6 the windbreak walls were discussed in detail. Moreover, thermal performance is

7 influencedby crosswind in the same manner at different ambient temperatures.Ma et

8 al. [12] also compared the effects of crosswind and ambient temperature on the dry

9 cooling tower performance with numerical simulation coupling the tower and

10 condenser. The pressure, temperaturefields and streamlines were presented in their

11 study, and parameters of the system under steady state were obtained. Results

12 indicated that outlet water temperature of the tower isapproximately linear with

13 ambient temperature, whereas nonlinear with crosswind, and reasons for this

14 conclusion were explained in detail. In addition,the computational models and

15 coupled method mentioned in their paper were proved reliable by operation data.

16 Although numerical simulation is quite popular in the research of the NDDCT,

17 it's never an easy job owing to the large scale of the tower and different geometric

18 sizes of different towers. Therefore, a simple theoretical tool is much needed for

19 scaling of such buoyancy-induced flows. Hooman[13] simplified heatexchanger as

20 porous media, presented scaling laws for the drycooling tower, and studied the

21 turbulent free convection throughthe heat exchanger bundles and along the cooling

22 tower. Then, with scale analysis, he further presented a simple theoretical modelto 
1 predict the effect of crosswind on the performance of the NDDCT [14]. It's uplifting

2 to see the simple theoretical model established by Hooman has a good agreement with

3 available experimental data, and the maximum relative error is observed to be $15 \%$.

4 However, as forhis model, there still exists two main problems. The first one is

5 that his theoretical model can't evaluate heat transfer variation caused by ambient

6 temperature, while ambient temperature plays a crucial role in thermal performance of

7 the NDDCT. The other problem is that no method is presented in his model to

8 calculate the key parameter (i.e. outlet air velocity at tower exit under windless

9 condition, expressed as $\left.\left(V_{o, n}\right)_{N W}\right)$, based on which can heat transfer variation caused

10 by crosswind be obtained. $\left(V_{o, n}\right)_{N W}$ is closely related to the structure and size of the

11 tower, and there is no fixed $\left(V_{o, n}\right)_{N W}$ for different NDDCTs. In addition, $\left(V_{o, n}\right)_{N W}$

12 varies with initial temperature difference. Under a lager initial temperature difference,

13 the more airflow will be drafted into the tower, which induces the increase of $\left(V_{o, n}\right)_{N W}$.

14 On the whole, a method is much needed for the calculation of $\left(V_{o, n}\right)_{N W}$ for different

15 NDDCTs under various initial temperature differences.

16 This study aims to establish a newtheoretical model based on some theories from

$17 \mathrm{Ma}[12]$ and Hooman [14]. In this new theoretical model, both the impactsof ambient

18 temperature and crosswind on thermal performance of the tower are taken into

19 account, and an algorithm is introduced to get the velocity of air flowing out of the

20 NDDCT. Using this model, heat rejection and outlet water temperature of the tower at

21 any specified ambient conditioncan be easily generated with the data of reference

22 condition obtained in advance.In addition to the example of a $600 \mathrm{MW}_{\text {th }}$ NDDCT, the 
1 new theoretical model is also verified by other NDDCTs researched in the existing

2 literatures.

3 2. Theoretical analysis of heat transfer variation caused by ambient

4 temperature

The driving force in a NDDCT is the air density difference that, following the use of Boussinesq approximation, takes the following form[13]:

$$
F_{D}=\rho_{a} g H_{T} \beta_{a}\left(t_{a, m}-t_{a}\right)(1)
$$

Here, under windless condition, flow and temperature fields of air in or around the tower areaxially symmetric. In Ref [10], the difference between thehighest temperature located near the radiator and the lowest temperature at thecentre of the tower is only $1.1^{\circ} \mathrm{C}$, and that is $1.2^{\circ} \mathrm{Cin}$ Ref [5]. Thus, the distribution of air temperature inside the tower is nearly uniform, and taking $t_{a, m}$ as the average temperature of internalwarm air under windless condition is reasonable.

When air passes through the tower, the resistance of tower to airflow is the sum of the resistance of each part of the tower. Theresistance of each part is proportional to the dynamic head of air passing through this part. To simplify the calculation, resistancecoefficient of each partis normalized to the heat exchanger inlet velocity and area, and then adding up all these converted resistancecoefficients, the overall resistance coefficient is obtained.Therefore, the resistance of the tower is expressed as follows:

According to the equality between the draft and resistance of the tower, it can be 
1 obtained combining Eqns. (1) and (2):

2

$$
t_{a, m}-t_{a}=\frac{K_{T} V_{i, n}^{2}}{2 \beta_{a} g H_{T}}(3)
$$

As for heat transfer between water and air at the tower entrance, the conductive thermal resistance through the tube wall and the convective thermal resistance of water are minor and can be neglected, compared with the convective thermal resistance of air. Thus, heat transfer at the tower entrance can be regarded as convective heat transfer between tube wall and air.Using lumped parameter radiator model $[1,3,5,6]$, the tube wall temperature can be replaced with mean water temperature, andthe amount of heat transferred from hot water to cold air is:

$$
\begin{array}{r}
Q_{T}=h A_{e}\left(\frac{t_{w 1}+t_{w 2}}{2}-t_{a}\right)(4) \\
Q_{T}=\rho_{a} V_{i, n} A_{i} c_{p, a}\left(t_{a, m}-t_{a}\right)(5) \\
Q_{T}=m_{w} c_{p, w}\left(t_{w 1}-t_{w 2}\right)(6)
\end{array}
$$$$
\text { The air sideconvectiveheattransfercoefficient, }
$$$$
h \text {, }
$$
isafunctionofnormalvelocitycomponent[1-3], and can be specified as the following form:

$$
h=c V_{i, n}{ }^{f}(7)
$$

Where $c$ and $f$, which are performance parameters of heat exchanger, are specified as constants.

Combining Eqns. (3), (4), (5) and (7), it can be obtained:

$$
\frac{t_{w 1}+t_{w 2}}{2}-t_{a}=\frac{\rho_{a} A_{i} c_{p, a} K_{T}}{2 c A_{e} \beta_{a} g H_{T}} V_{i, n}{ }^{3-f}
$$

In Eq. (8), $c, A_{e}, A_{i}$ and $H_{T}$ are parameters of the tower or heat exchanger, and 
1 remain constant for a certain NDDCT. $\rho_{a}, \beta_{a}$ and $c_{p, a}$, which vary little with ambient

2 temperature, are treated as constants.g, which is local gravitational acceleration, is

3 specified. The overallresistancecoefficient of the tower, $K_{T}$, is assumed as invariable

4 regardless of temperature difference of heat exchanger here, because for most parts of

5 the tower, the resistancecoefficient is dependent on structure and size of this part[15,

6 16]. Then, Eq. (8) can be changed as the following form:

The heat transfer ratio $\left(\varepsilon_{a}\right)$, which reflects thermal performance variationof the NDDCTwith ambient temperature, is expressed as:

$$
\varepsilon_{a}=\frac{Q_{T}}{Q_{T}{ }^{0}}
$$

With Eqns. (4), (7), (9) and (10), $\varepsilon_{a}$ is changed as the following form:

$$
\varepsilon_{a}=\frac{Q_{T}}{Q_{T}{ }^{0}}=\left(\frac{\frac{t_{w 1}+t_{w 2}}{2}-t_{a}}{\frac{t_{w 1}^{0}+t_{w 2}^{0}}{2}-t_{a}^{0}}\right)^{\frac{3}{3-f}}
$$

In Eq. (11), the variable of $t_{w 2}$ is unknown, and will be calculated by Eq. (6) after

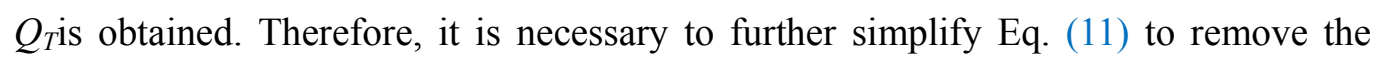
unknown variable. Next, a simplified method is introduced.

As has been well explained in Ref [12], when ambient temperature increases, heat rejection of the tower drops sharply, but will be offset by the overall ascent of cooling water temperature, and the indirect dry cooling system reaches to another steady state. Compared with the initial state, final heat rejection drops tinily. Moreover, in steady state, the inlet and outlet water temperature of the tower increases 
1 linearly with ambient temperature, shown in Figure 1.Physically, lines $\mathrm{L}_{\mathrm{w} 1}$ and $\mathrm{L}_{\mathrm{w} 2}$

2 means inlet and outlet water temperatures of the tower at different ambient

3 temperatures in steady state respectively. Geometrically, the equations of lines $\mathrm{L}_{\mathrm{w} 1}$

4 and $\mathrm{L}_{\mathrm{w} 2}$ can be expressed as $y=t_{w 1}$ and $y=t_{w 2}$ respectively. As mentioned above, after

5 ambient temperature increases, the final cooling capability of the tower can'trecover to,

6 and is smaller than that of initial steady state. Therefore, the slope of line $\mathrm{L}_{\mathrm{w} 2}$ is larger

7 than that of line $\mathrm{L}_{\mathrm{w} 1}$, and lines $\mathrm{L}_{\mathrm{w} 1}$ and $\mathrm{L}_{\mathrm{w} 2}$ intersect at Point $\mathrm{A}$. Then, line $\mathrm{L}_{\mathrm{w}}$ with the

8 equation of $y=\left(t_{w 1}+t_{w 2}\right) / 2$ can be drawn through Point $\mathrm{A}$, at which the dry cooling

9 tower loses heat transfer ability. This is caused by the equality of inlet water

10 temperature of the tower $\left(t_{w 1}\right)$ and ambient temperature $\left(t_{a}\right)$, i.e. heat transfer

11 temperature difference of the tower is zero in this condition. Therefore, line $\mathrm{L}_{\mathrm{a}}$ with

12 the equation of $y=t_{a}$ passes through Point A as well.Then,two running states of the

13 tower are pointed out in Figure 1, one is under reference condition with ambient

14 temperature of $t_{a}^{0}$, and the other is under any condition with ambient temperature of $t_{a}$.

15 Lengths of segment $B E, B D$ are equal to the values of $t_{w 1}^{0}-t_{a}^{0}, \frac{t_{w 1}^{0}+t_{w 2}^{0}}{2}-t_{a}^{0}$

16 respectively, and lengths of segment $F I, F H$ are equal to the values of $t_{w 1}-t_{a}$,

$17 \frac{t_{w 1}+t_{w 2}}{2}-t_{a}$ respectively. According to the theory of similar triangles, it can be 18 obtained:

$$
\frac{F I}{B E}=\frac{F H}{B D}=\frac{F A}{B A}(
$$

20 That is,

$$
\frac{t_{w 1}-t_{a}}{t_{w 1}^{0}-t_{a}^{0}}=\frac{\frac{t_{w 1}+t_{w 2}}{2}-t_{a}}{\frac{t_{w 1}^{0}+t_{w 2}^{0}}{2}-t_{a}^{0}}
$$


1 Here, it's important to note that Point A in Figure 1 can't be the actual point of the

2 physical process.Because Point A means no heat transfer in the cold-end system of

3 power plant, while any thermodynamic cycle can hardly do without cold source

4 according to the second law of thermodynamics. In addition, there is a safe range of

5 ambient temperature during the practical operation of the indirect dry cooling system.

6 Ambient temperature affects outlet water temperature of the tower, and then impact

7 backpressure of the condenser. However, too large or too small backpressure will

8 affect the safe operation of the system. Thus, for the safe operation of the system,

9 there exists upper and lower bound of ambient temperature, which can be calculated

10 based on specified system under specified conditions.

$11 t_{w 1}-t_{a}$ is named initial temperature difference of the NDDCT, expressed as:

Then, with Eqns. (11), (13) and (14), $\varepsilon_{a}$ is finally simplified as follows:

$I T D=t_{w 1}-t_{a}(14)$

heat and thermal expansion coefficient are treated as temperature independent, and

17 then the sensitivity of such assumption is discussed. With Eqns (3) and (5), it can be obtained:

$$
Q_{T}=\frac{\rho_{a} A_{i} K_{T} c_{p, a}}{2 \beta_{a} g H_{T}} V_{i, n}{ }^{3}
$$

Treating air as ideal gas, the ideal gas equation can be written as:

$$
\frac{p}{\rho_{a}}=R_{a} t_{a}
$$


$1 \quad$ As $\beta_{a}$ is equal to $1 / t_{a}$, then Eq. (16) can be changed as:

2

$$
Q_{T}=\frac{p A_{i} K_{T} c_{p, a}}{2 R_{a} g H_{T}} V_{i, n}^{3}
$$

Though $c_{p, a}$ which we set as constant should increase slightly with ambient temperature and $Q_{T}$ will be exaggerated with our method at low ambient temperature, this deviation is tiny and negligible for $c_{p, a}$ varies little with ambient temperature.

\section{Theoretical analysis of heat transfer variation caused by crosswind}

As has been well documented in literatures $[8,10]$, crosswind plays the role of a wind-cover and leads to a reduction in air exit mass flow rate, which further affects the tower intake and reduces cooling efficiency of the tower. Under windless condition, the generated plume rises vertically. With the increase of crosswind velocity, the plume that rises out of the tower gets deflected. A deflection angle $\theta$ is defined as the angle between normal plume rise pathlines (under windless conditions)and the actual flow pathlines (under windy conditions), as shown in Figure 2. To describe the relationship between velocity vectors and plume rise pathlines, a tangent function is defined as:

$$
V_{W}=\left(V_{o, \mathrm{n}}\right)_{N W} \tan (\theta)(19)
$$

The tangent curve suggested in Eq. (19) is proved acceptable in Ref [14], and thevariation of outlet air velocity compared to windless case is also researched and explained. A thin control volume, only extended to a short heightoutside the tower from a short distance inside the tower, is assumed around the tower exit, as shown in Figure2. Due to the effect of crosswind, the rising plume gets deflected, and only normal component of the velocity can rise up and carry heat out of the tower while the 
1 radial componentdrags apart of the rising plume away creating a circulating region. As

2 a result, the effective velocity out of the tower under crosswind can be expressed as:

3

4

$$
\left(V_{o, n}\right)_{W}=\left(V_{o, n}\right)_{N W} \cos (\theta)(20)
$$

With Eqns. (19) and (20), it can be obtained:

$$
\frac{\left(V_{o, n}\right)_{W}}{\left(V_{o, n}\right)_{N W}}=\frac{1}{\sqrt{1+\left(\frac{V_{W}}{\left(V_{o, n}\right)_{N W}}\right)^{2}}}
$$
considering the same initial temperature difference of the NDDCTdue tothe same ambient temperature, he regarded the variation of heat transfer coefficient as the main reason for thermal performance variation of the tower under windy conditions, and simplified heat transfer ratio (windy divided by no wind) as:

$$
\varepsilon_{W}=\frac{\left(Q_{T}\right)_{W}}{\left(Q_{T}\right)_{N W}}=\frac{(h)_{W}}{(h)_{N W}}(22)
$$

Considering mass conservation of airflow in and out of the tower, it can be obtained that:

$$
A_{i} V_{i, n}=A_{o} V_{o, n}=A_{s} V_{s, n}(23)
$$

Then, Eq. (7) can be changed as the following form:

$$
h=c\left(\frac{A_{o}}{A_{i}}\right)^{f} V_{o, n}^{f}(24)
$$

As a consequence, the heat transfer ratio (windy divided by no wind), $\varepsilon_{w}$, will be only a function of variation in air velocity, combining Eqns. (21),(22) and (24).

$$
\varepsilon_{W}=\frac{\left(Q_{T}\right)_{W}}{\left(Q_{T}\right)_{N W}}=\frac{(h)_{W}}{(h)_{N W}}=\left(\frac{\left(V_{o, n}\right)_{W}}{\left(V_{o, n}\right)_{N W}}\right)^{f}=\left(1+\left(\frac{V_{W}}{\left(V_{o, n}\right)_{N W}}\right)^{2}\right)^{-\frac{f}{2}}
$$


1 In Eq. (25), normal outlet air velocity under windless condition, $\left(V_{o, n}\right)_{N W}$, is

2 unknown, as a result, the basic job for calculation is to get $\left(V_{o, n}\right)_{N W}$.Here analgorithm

3 is introduced to get $\left(V_{o, n}\right)_{N W}$, and then obtain $\left(Q_{T}\right)_{W}$ under any ambient condition with

4 initial temperature difference of ITD and crosswind velocity of $V_{W}$. Flow chart of the

5 new theoretical modelfor thermal calculations of the NDDCT under variable ambient

6 conditions is shown in Figure3.

7 (1).First of all, a reference condition should be defined. It is better to take the 8 condition under which thermal performance experiment of the tower is carried out as

9 reference condition, because this thermal performance experiment is required before 10 the operation of a newly built dry cooling tower, and we could get 11 abundantexperimental data of performance parameters of the tower, like $\left(t_{a}\right)_{W}^{r e f}$, $12\left(t_{a, m}\right)_{W}^{r e f},\left(t_{w 1}\right)_{W}^{r e f},\left(t_{w 2}\right)_{W}^{r e f},\left(V_{i, n}\right)_{W}^{r e f}, V_{W}^{r e f}, m_{w}$ and so on. Generally, $\left(t_{a, m}\right)_{W}^{r e f}$ and $13\left(V_{i, n}\right)_{W}^{r e f}$ are hard to measure, and we just need to know one of them.

(2).Next we need do some calculations. ITD ${ }^{\text {ref }}$ is obtained by Eq. (14), and $15\left(Q_{T}\right)_{W}^{r e f}$ is obtained by Eq. (6). To get $\left(Q_{T}\right)_{N W}^{r e f}$ by Eq. (25), we need to know $16\left(V_{o, n}\right)_{N W}{ }^{r e f}$ in advance, and $\left(V_{o, n}\right)_{N W}{ }^{r e f}$ can be calculated by solving Eq. (21),once $17 \quad\left(V_{o, n}\right)_{W}{ }^{r e f}$ is obtained.

$$
\left(V_{o, n}\right)_{N W}^{r e f}=\sqrt{\frac{\left(\left(V_{o, n}\right)_{W}{ }^{r e f}\right)^{2}+\left(V_{o, n}\right)_{W}{ }^{r e f} \sqrt{\left(\left(V_{o, n}\right)_{W}{ }^{r e f}\right)^{2}+4\left(V_{W}{ }^{r e f}\right)^{2}}}{2}}
$$

19 There are two ways to get $\left(V_{o, n}\right)_{W}{ }^{r e f}$. The first way is to compute $\left(V_{o, n}\right)_{W}{ }^{\text {ref }}$ directly 20 with $\left(V_{i, n}\right)_{W}{ }^{r e f}$ by Eq. (23), and the second way is to compute $\left(V_{o, n}\right)_{W}{ }^{r e f}$ indirectly by 21 Eq. (23) after $\left(V_{i, n}\right)_{W}^{r e f}$ is obtained by Eq. (5). 
1 (3).After $\left(V_{o, n}\right)_{N W}^{r e f}$ and $\left(Q_{T}\right)_{N W}^{\text {ref }}$ are obtained, we can easily

2 calculateperformance parameters of the tower under any ambient condition with

3 initial temperature difference of ITD and crosswind velocity of $V_{W}$. By Eq. (15),

$4 \quad\left(Q_{T}\right)_{N W}$ is obtained, and it can be deduced with Eqns. (9), (13), (14) and(23):

5

6

7

$$
\frac{\left(V_{o, n}\right)_{N W}}{\left(V_{o, n}\right)_{N W}^{r e f}}=\left(\frac{I T D}{I T D^{r e f}}\right)^{\frac{1}{3-f}}
$$

Therefore, $\left(V_{o, n}\right)_{N W \text { is }}$ exported by Eq. (27). After that, $\left(Q_{T}\right)_{W}$ is calculated according to Eq. (25), and $\left(t_{w 2}\right)_{W}$ is obtained by Eq. (6)as well.

Although the above theoretical model is simple and fast in thermal performance prediction of the NDDCT, it has the restriction, that is, according to Eq. (25)proposed firstly byHoomon[14], heat transfer efficiency decreases with crosswind, which disagrees with the relationship reported in Refs.[6, 12, 17]under a very high crosswind velocity.For the NDDCTs with heat exchanger arranged vertically, there exists a critical wind velocity, at which hydraulic performance of the dry cooling tower is most deteriorated with mass flow rate of intake air and heat rejection of the tower reaching to their minimum values, and outlet water temperature of the tower reaching to its maximum value at constant inlet water temperature. Moreover, heat rejection of the tower decreases with crosswind velocity lower than the critical wind velocity, whereas increases with crosswind velocity higher than the critical wind velocity.The reason is that under windy conditions, thermal performances of upwind radiators are superior to otherradiators, and air mass flow rates of upwind radiators increase with crosswind, while those decrease for other radiators. With the increase of crosswind velocity up to the critical wind velocity, thermal performance of the whole tower is 
1 directly dependent on thermal performances of upwind radiators, because intake air

2 mass flow rates and heat rejections of other radiators vary slightly, and are

3 incomparable with those of upwind radiators. In this case, the NDDCT acts more like

4 a forced draft cooling tower with air flow pushed in from upwind radiators, inducing

5 the increment of heat transfer efficiency, while the above theoretical model for

6 evaluating wind-caused heat transfer variation with crosswind isunavailable any more

7 under this condition. As a result, the following testing work is conducted at crosswind

8 velocity lower than the critical wind velocity. The critical wind velocity is related to

9 geometric parameters of the tower, and is no less than $10 \mathrm{~m} / \mathrm{sfor}$ a NDDCT with base

10 diameter lager than 100m,combining Refs. $[6,10,12,17]$.

\section{Model validation and results analysis}

It is convenient to obtain thermal parameters of the NDDCT under any specified ambient conditionwith above new theoretical model. A600MW $\mathrm{MW}_{\text {th }}$ Hamon-type NDDCT is taken as an example. The tower is a hyperbolic shell-type tower, at the base of which air-cooled heat exchanger is arranged vertically. Specific parameters of the tower and heat exchanger are shown in Table 1.Thermal performance experiment of the tower was carried out, and measurement point arrangement is shown in Figure 4. Crosswind velocity is measured at the height of $10 \mathrm{~m}$ with the cup anemometer accurate to $\pm(0.3+0.03 \mathrm{~V}) \mathrm{m} / \mathrm{s}$. Four measurement points of crosswind velocity are arranged $40 \mathrm{~m}$ away outside the tower. Air temperature is measured with pt100 temperature sensor accurate to $\pm(0.15+0.2 \% t)^{\circ} \mathrm{C}$. Ten measurement points of ambient temperature are arranged $1 \mathrm{~m}$ away around the tower at half of the radiator height, and 
1 three measurement points of inside air temperature are equidistantly set along radius

2 direction. Both the inlet and outlet water temperature are measured at the main pipe

3 with pt100 temperature sensor accurate to $\pm(0.3+0.5 \% t)^{\circ} \mathrm{C}$, and mass flow rate of

4 water is measured by ultrasonic flowmeter with accuracy of $\pm 1 \%$. All the processed

5 experimental data is listed in Table 2.

6 With above original data of reference condition, operating parameters of the

7 tower under any ambient condition are obtained using thenew theoretical model

8 proposed in this paper.Table 3 presents the comparison of calculated results

9 withmeasurementdataof the tower under different ambient conditions. The first ten sets

10 of measurementdata taken from control system of the unit is averaged by a period of

11 time,during whichpowerunit is stable running withhardly any fluctuations, and the

12 second ten sets ofmeasurementdata is provided by Ref [12], owing to the same

13 NDDCT researched in Ref [12] and this paper. As seen, theoretical approximate

14 calculations are agreeing well withmeasurementdata of the tower, and the maximum

15 error of $\left(Q_{T}\right)_{W}$ using this newtheoretical model is found to be less than $8 \%$.

16 Considering the mutability and complexity of practical operation of the indirect dry

17 cooling system, the error is acceptable in engineering application.

18 Variation of heat transfer ratio $\varepsilon_{W}$ with crosswind velocity $V_{W}$ is shown in Figure 5.

19 There is no doubt that $\varepsilon_{W}$ decreases with the increase of $V_{W}$. Moreover variation of heat

20 transfer ratio $\varepsilon_{W}$ is closely related to initial temperature difference ITD. Under the lager

$21 I T D, \varepsilon_{W}$ drops more slowly with $V_{W}$. The reason is that the lager ITDis, the more air the

22 tower draws in, and thedeflection of the rising plume caused by crosswind reduces. 
1 That is, under the lager ITD, the tower has the lager outlet air velocity under windless

2 condition $\left(V_{o, n}\right)_{N W}$, and then under the same crosswind velocity, the tower has the

3 larger resistance to crosswind, which makes cooling efficiency declines more

4 slowly.Table 4lists $\left(V_{o, n}\right)_{N W}$ of different NDDCTs under various conditions. As

5 seen, $\left(V_{o, n}\right)_{N W \text { is }}$ closely related tostructure and size of the tower, and for a certain

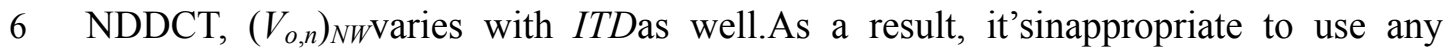

7 constant $\left(V_{o, n}\right)_{N W}$ for calculation, and to get accurate variation of heat transfer ratio $\varepsilon_{W}$

8 with crosswindvelocity $V_{W},\left(V_{o, n}\right)_{N W}$ should be clearly obtained in advance.

Variation of $\left(Q_{T}\right)_{W}$ with ITD is shown in Figure6, and

$10\left(Q_{T}\right)_{W}$ increasesalmostlinearlywith ITD. The larger ITD, which means the larger

11 temperature difference of heat exchanger, causesthe increase of heat rejection of the

tower with other conditions unchanged. The variation of ambient temperature has

13 little impact on heat rejection distribution of the tower among sectors and leads to the

14 uniform variation of heat transfer of all sectors [12]. This brings the comprehensive

15 effect that heat rejection and outlet water temperature of the tower increases and

16 decreases linearly with the drop of ambient temperature atconstant inlet water

17 temperature(i.e.linearlywith the increase of ITD) respectively, which is in accord with

18 the conclusion of $\mathrm{Su}[10]$.However, the relationships of $I T D$ to $\left(Q_{T}\right)_{W}$ (i.e. the slopes of

19 these lines in Figure 6) are different at various crosswind velocities. The slope, which

20 means the growth of $\left(Q_{T}\right)_{W}$ for each degree rise in ITD, is larger under a smaller

21 crosswind velocity. That is ITD has a greater impact on cooling capability of the tower

22 under a smaller crosswind velocity, and heatrejection of the tower increases more 
1 rapidly with $I T D$ under a smaller crosswind velocity.

2 The newtheoretical model for thermal performance prediction of the NDDCT

3 can be used following more than the procedure showed in Figure 3. One can change

4 calculation order flexibly, as long as the number of the distinct equations employed is

5 no less than the number of the unknown variables in these equations.Then, the new

6 theoretical model is flexibly applied to thermal calculation for other NDDCTs. Figure

77 shows the resultscalculated by presentnew theoretical model versus the data

8 available in $\operatorname{Ref}[10]$. As seen, theoretical calculations agree well with the simulations

9 under various ambient temperatures (Figure 7(a)) and crosswind velocities (Figure

$107(b))$. Testing work for another NDDCT researched in Refs $[17,19]$ is conducted as

11 well using thisnew theoretical model, as shown in Figure 8. When ambient

12 temperature increases from $32^{\circ} \mathrm{C}$ to $42^{\circ} \mathrm{C}$, the increment of outlet water temperature is

13 reported to be $10.5^{\circ} \mathrm{C}$, which is close to the increment of $10.0^{\circ} \mathrm{C}$ obtained with

14 thistheoretical model, as shown in Figure 8(a). The variation of outlet water

15 temperature with crosswind coincides well with that in Ref [17] under crosswind

16 velocity less than the critical wind velocity, as shown in Figure 8(b).For a NDDCT

17 with base diameter lager than $100 \mathrm{~m}$, the critical wind velocity is usually larger than

$1810 \mathrm{~m} / \mathrm{s}$, which is generally large and uncommon during the practical operation of the

19 tower. In consequence, the present theoretical model is still feasible for thermal

20 performance prediction, which has been verified by above testing work.

21 5. Conclusion

22 Based on previoustheories, a newtheoretical model is proposed to calculate heat 
1 rejection of the tower under any specified ambient condition. The theoretical model

2 considers both the effects of ambient temperatureandcrosswindonthermal performance

3 of the tower. When evaluating wind-caused heat transfer variation, analgorithm is

4 introduced to get the keyparameter (i.e. outlet air velocity at tower exit under windless

5 condition), which is related to not only the structure and size of the tower, but also the

6 initial temperature difference.

7 The new theoretical model is unsuitable for the condition with crosswind

8 velocity higher than the critical wind velocity, which is generally large and

9 uncommon in the practical operation of the tower. As a result, the theoretical model is

10 still meaningful for thermal performance predictions of the NDDCTs, and it is

11 demonstrated effective by the example of a $600 \mathrm{MW}_{\text {th }}$ NDDCT with the maximum

12 error of heat rejectionless than $8 \%$. The example analysis shows that under a lager

13 initial temperature difference, the tower has the larger resistance to crosswindand the

14 cooling efficiency declines more slowly, furthermore, heat rejection of the tower

15 increases more rapidly with initial temperature difference under a smaller crosswind

16 velocity.

17 Changing calculation order, the new theoretical modelcan be applied flexibly, as

18 long as the number of the distinct equations employed is no less than the number of

19 the unknown variables in these equations. Testing work for the other two NDDCTs is

20 conducted using this theoretical model, and the predictions have a satisfied agreement

21 with results available in the existing literatures.Testing work re-verifies the

22 effectiveness of thenew theoretical model, which is available for thermal performance 
prediction of the NDDCT and beneficial foroperation decision of the tower. 


\section{Nomenclature}

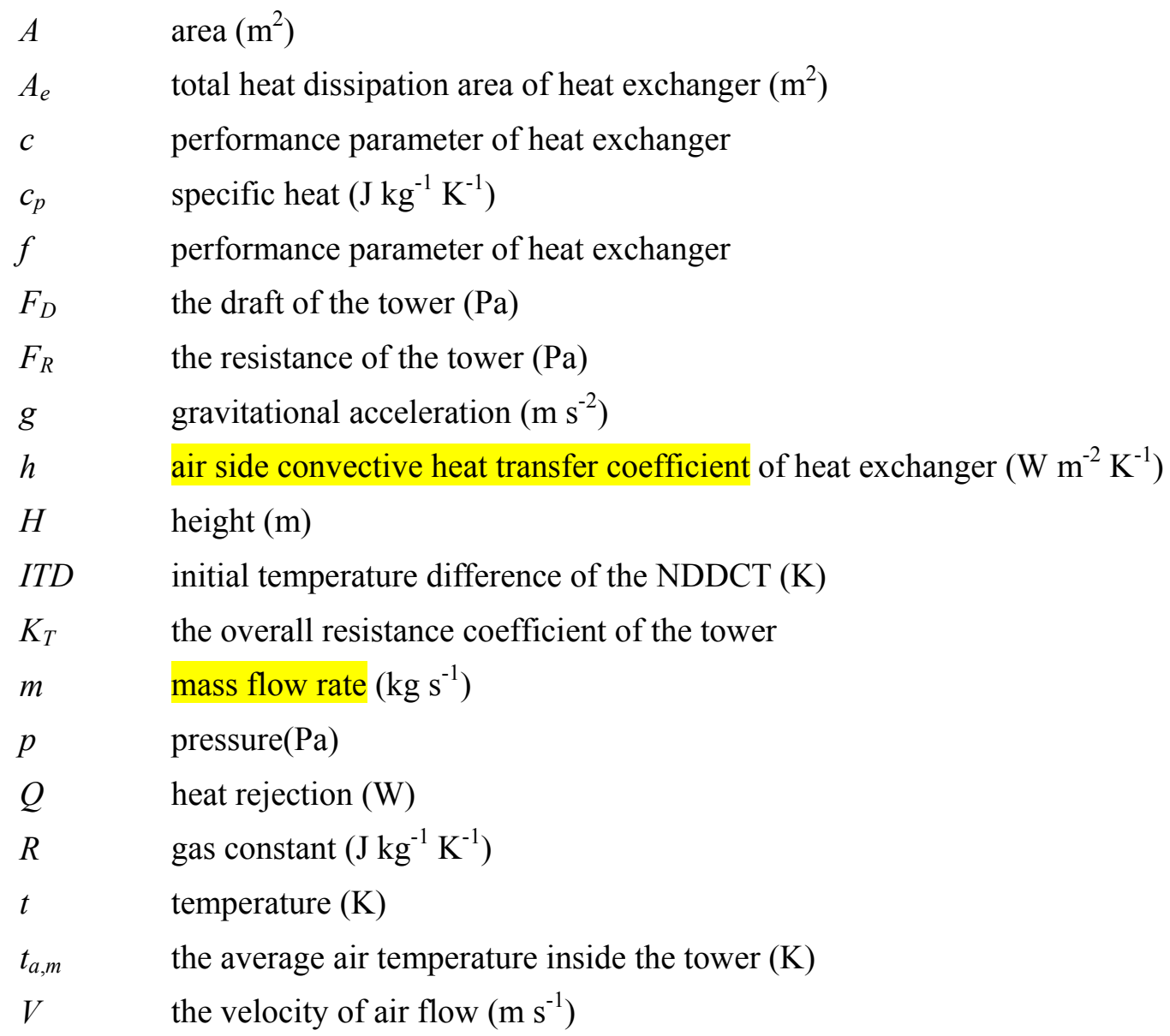




$\begin{array}{ll}S & \text { any section of the tower } \\ T & \text { tower } \\ w & \text { circulating cooling water } \\ W & \text { crosswind } \\ 1 & \text { inlet } \\ 2 & \text { outlet }\end{array}$

\section{Acknowledgements}

The financial support for this research, from the National Science Foundation of China (Grant No. 51176030) and China Power International Development Limited(Grant No. 2013-006-ZDG-KJ-X) is gratefully acknowledged.

\section{Reference}

[1] Zhai Z, Fu S. Improving cooling efficiency of dry-cooling towers under cross-wind conditions by using wind-break methods. Applied Thermal Engineering 2006; 26(10): 1008-1017.

[2] Goodarzi M. A proposed stack configuration for dry cooling tower to improve cooling efficiency under crosswind. Journal of Wind Engineering and Industrial Aerodynamics 2010; 98(12): 858-863.

[3] Al-Waked R, Behnia M. The effect of windbreak walls on the thermal performance of natural draft dry cooling towers. Heat Transfer Engineering $2005 ; 26(8): 50-62$.

[4] Jahangiri A, Golneshan A. Feasibility study of the thermal performance improvement of natural draft dry cooling towers due to flue gas injection. World Applied Science Journal 2011; 12(4): 568-575. 
[5] Al-Waked R., Behnia M. The performance of natural draft dry cooling towers under crosswind: CFD study. International Journal of Energy Research 2004; 28(2): $147-161$.

[6] Yang LJ, Wu XP, Du XZ, Yang YP. Dimensional characteristics of wind effects on the performance of indirect dry cooling system with vertically arranged heat exchanger bundles. International Journal of Heat and Mass Transfer 2013;67: $853-866$.

[7] Ardekani MA, Farhani F, Mazidi M. Effects of cross wind conditions on efficiency of Heller dry cooling tower. Experimental Heat Transfer 2015;28(4): 344-353.

[8] Wei QD, Zhang BY, Liu KQ, Du XD, Meng XZ. A study of the unfavorable effects of wind on the cooling efficiency of dry cooling-towers. Journal of Wind Engineering and Industrial Aerodynamics 1995; 54: 633-643.

[9] Goodarzi M, Amooie H. A proposed heterogeneous distribution of water for natural draft dry cooling tower to improve cooling efficiency under crosswind. IEEE 4th Conference onThermal Power Plants (CTPP), Tehran, Iran, 2012: 1-6.

[10] $\mathrm{Su}$ MD, Tang GF, Fu S. Numerical simulation of fluid flow and thermal performance of a dry-cooling tower under cross wind condition. Journal of Wind Engineering and Industrial Aerodynamics 1999; 79(3): 289-306.

[11] DuPreez AF, Kroger DG. The effect of the heat exchanger arrangement and wind-break walls on the performance of natural draft dry-cooling towers subjected to cross-winds. Journal of Wind Engineering and Industrial 
Aerodynamics 1995; 58(3): 293-303.

[12] Ma H, Si FQ, Li L, Yan WS, Zhu KP. Effects of ambient temperature and crosswind on thermo-flow performance of the tower under energy balance of the indirect dry cooling system. Applied Thermal Engineering 2015; 78: 90-100.

[13] Hooman K. Dry cooling towers as condensers for geothermal power plants. International Communications in Heat and Mass Transfer 2010; 37(9): 1215-1220.

[14] Hooman K. Theoretical prediction with numerical and experimental verification to predict crosswind effects on the performance of cooling towers. Heat Transfer Engineering 2015; 36(5): 480-487.

[15] Du Preez AF, Kröger DG. Experimental evaluation of aerodynamic inlet losses in natural draft dry cooling towers. Proceedings of the 6th IAHR Cooling Tower Workshop, Pisa, Italy, 1988.

[16] Buys JD, Kroeger DG. Cost-optimal design of dry cooling towers through mathematical programming techniques. Journal of Heat Transfer-Transactions of the ASME1989; 111(1-4): 322-327.

[17] Zhao, YB, Long GQ, Sun FZ, Li Y, Zhang CJ. Numerical study on the cooling performance of dry cooling tower with vertical two-pass column radiators under crosswind. Applied Thermal Engineering2015; 75: 1106-1117.

[18] Liao HT, Yang LJ, Du XZ, Yang YP. Influences of height to diameter ratios of dry-cooling tower upon thermo-flow characteristics of indirect dry cooling system. International Journal of Thermal Sciences 2015; 94: 178-192. 
[19] Zhao YB, Sun FZ, Li Y, Long GQ, Yang Z. Numerical study on the cooling performance of natural draft dry cooling tower with vertical delta radiators under constant heat load. Applied Energy 2015; 149: 225-237. 


\section{Table caption}

Table 1. Geometric parameters of the tower and performance parameters of heat exchanger

Table 2. Data collection of measurement points in the experiment of the NDDCT

Table 3. The comparison of results calculated by presented theoretical model with measurement dataunder the measurement conditions

Table 4. Outlet air velocities of different NDDCTs under windless condition with various initial temperance differences 


\section{Figure caption}

Figure 1. The relationship of cooling water temperature with ambient temperature

Figure 2. The relationship of outlet air velocity under windless condition with crosswind velocity and the variation of outlet air velocity caused by crosswind

Figure 3. Flow chart of the new theoretical model for thermal calculation of the NDDCT under variable ambient conditions

Figure 4. Measurement points arrangement for thermal performance experiment of the NDDCT

Figure 5. Variations of heat transfer ratio $\varepsilon_{W}$ with crosswind velocity $V_{W}$ under different ITDs

Figure 6. Variations of heat rejection of the tower $\left(Q_{T}\right)_{W}$ with ITD under different crosswind velocities

Figure 7. Comparison of predictions by present theoretical model and simulations in Su et al. [10], (a) in the condition: $V_{W}=0 \mathrm{~m} / \mathrm{s},\left(t_{w 1}\right)_{W}=43^{\circ} \mathrm{C}$; (b) in the condition: $\left(t_{w 1}\right)_{W}=43^{\circ} \mathrm{C},\left(t_{a}\right)_{W}=15^{\circ} \mathrm{C}$

Figure 8. Comparison of predictions by present theoretical model and results reported in Zhao et al. $[17,19]$, (a) in the condition: $\left(Q_{T}\right)_{W}=887.2 \mathrm{MW}, V_{W}=4 \mathrm{~m} / \mathrm{s}$; (b) in the condition: $I T D=29.2^{\circ} \mathrm{C}\left(\left(t_{w 1}\right)_{W}=43.1^{\circ} \mathrm{C},\left(t_{a}\right)_{W}=13.9^{\circ} \mathrm{C}\right) ; I T D=27.8^{\circ} \mathrm{C}$ $\left(\left(t_{w 1}\right)_{W}=39^{\circ} \mathrm{C},\left(t_{a}\right)_{W}=11.2^{\circ} \mathrm{C}\right)$ 
Title: A new theoretical method for predicating the part-load performance of natural draft dry cooling towers

Authors' names: Huan Ma, Fengqi Si *, Yu Kong, Wensheng Yan, Kangping Zhu

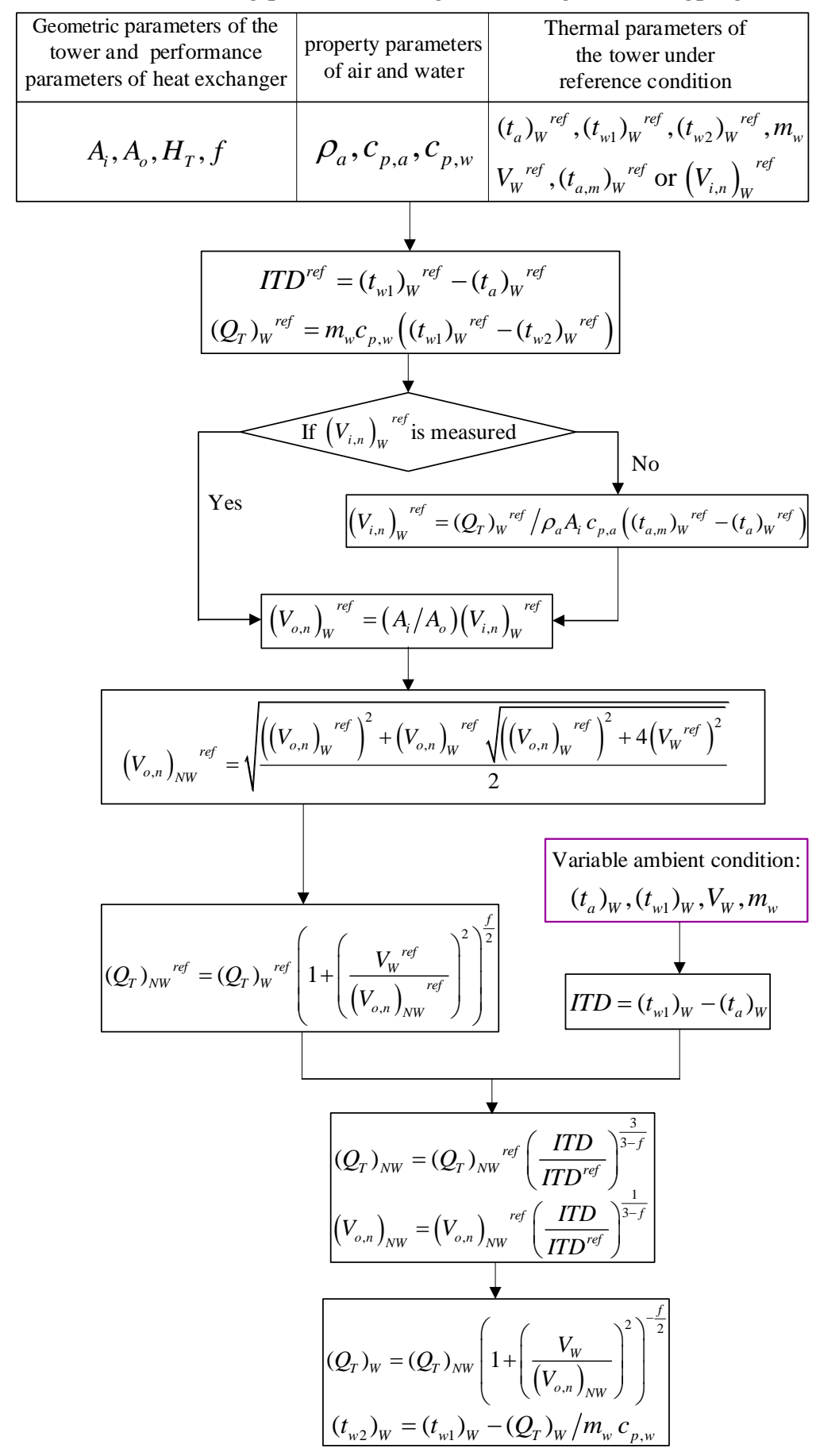

A new theoretical model is proposed for thermal calculation of natural draft dry cooling tower (NDDCT). Both the effects of ambient temperature and crosswind are taken into account in this model, in which an algorithm is introduced to get the velocity of air flowing out of the tower. Despite the ineffectiveness at crosswind speed higher than the critical wind speed, this model is still meaningful for thermal performance predication by the verification of different NDDCTs. 
Table 1:

Geometric parameters of the tower and performance parameters of heat exchanger

\begin{tabular}{lcc}
\hline & Unit & Value \\
\hline Base diameter of tower & $\mathrm{m}$ & 155 \\
Height of tower & $\mathrm{m}$ & 173 \\
Outlet diameter of tower & $\mathrm{m}$ & 91 \\
Throat diameter of tower & $\mathrm{m}$ & 88 \\
Height of heat exchanger & $\mathrm{m}$ & 30 \\
Total heat dissipation area of heat exchanger & $\mathrm{m}^{2}$ & 1588700 \\
Windward surface area of heat exchanger & $\mathrm{m}^{2}$ & 23396 \\
Performance parameter of heat exchanger $(c)$ & & 30.86 \\
Performance parameter of heat exchanger $(f)$ & & 0.41 \\
\hline
\end{tabular}


Table 2:

Data collection of measurement points in the experiment of the NDDCT

\begin{tabular}{|c|c|c|c|c|}
\hline Measurement point name & Symbol & Unit & Number & Value \\
\hline \multirow{11}{*}{ ambient air temperature } & \multirow{11}{*}{$\left(t_{a}\right)_{W}{ }^{r e f}$} & \multirow{11}{*}{${ }^{\circ} \mathrm{C}$} & 1 & 26.9 \\
\hline & & & 2 & 26.9 \\
\hline & & & 3 & 26.7 \\
\hline & & & 4 & 26.9 \\
\hline & & & 5 & 26.9 \\
\hline & & & 6 & 26.7 \\
\hline & & & 7 & 26.3 \\
\hline & & & 8 & 26.6 \\
\hline & & & 9 & 26.8 \\
\hline & & & 10 & 27.0 \\
\hline & & & average & 26.8 \\
\hline \multirow{4}{*}{ inside air temperature } & \multirow{4}{*}{$\left(t_{a, m}\right)_{W}^{r e f}$} & \multirow{4}{*}{${ }^{\circ} \mathrm{C}$} & 1 & 50.0 \\
\hline & & & 2 & 49.1 \\
\hline & & & 3 & 48.8 \\
\hline & & & average & 49.3 \\
\hline \multirow{3}{*}{ inlet water temperature } & \multirow{3}{*}{$\left(t_{w 1}\right)_{W}^{r e f}$} & \multirow{3}{*}{${ }^{\circ} \mathrm{C}$} & 1 & 59.7 \\
\hline & & & 2 & 59.6 \\
\hline & & & average & 59.7 \\
\hline \multirow{3}{*}{ outlet water temperature } & \multirow{3}{*}{$\left(t_{w 2}\right)_{W}^{r e f}$} & \multirow{3}{*}{${ }^{\circ} \mathrm{C}$} & 1 & 50.0 \\
\hline & & & 2 & 50.0 \\
\hline & & & average & $\mathbf{5 0 . 0}$ \\
\hline \multirow{5}{*}{ crosswind velocity } & \multirow{5}{*}{$V_{W}{ }^{r e f}$} & \multirow{5}{*}{$\mathrm{m} / \mathrm{s}$} & 1 & 2.8 \\
\hline & & & 2 & 2.6 \\
\hline & & & 3 & 2.6 \\
\hline & & & 4 & 2.5 \\
\hline & & & average & 2.6 \\
\hline water mass flow rate & $m_{w}$ & $\mathrm{t} / \mathrm{h}$ & & 70300 \\
\hline
\end{tabular}


Table 3:

The comparison of results calculated by presented theoretical model with

\begin{tabular}{|c|c|c|c|c|c|c|c|c|c|}
\hline \multirow{3}{*}{ case } & \multirow{3}{*}{$\begin{array}{l}\left(t_{a}\right)_{W} \\
{ }^{\circ} \mathrm{C}\end{array}$} & \multirow{3}{*}{$\begin{array}{l}V_{W} \\
\mathrm{~m} / \mathrm{s}\end{array}$} & \multirow{3}{*}{$\begin{array}{c}\left(t_{w 1}\right)_{W} \\
{ }^{\circ} \mathrm{C}\end{array}$} & \multirow{3}{*}{$\begin{array}{l}I T D \\
{ }^{\circ} \mathrm{C}\end{array}$} & \multirow{2}{*}{\multicolumn{2}{|c|}{$\begin{array}{c}\left(t_{w 2}\right)_{W} \\
{ }^{\circ} \mathrm{C}\end{array}$}} & \multirow{2}{*}{\multicolumn{2}{|c|}{$\begin{array}{l}\left(Q_{T}\right)_{W} \\
\mathrm{MW}\end{array}$}} & \multirow{3}{*}{$\begin{array}{c}\left(Q_{T}\right)_{W} \text { error } \\
\%\end{array}$} \\
\hline & & & & & & & & & \\
\hline & & & & & measurement & calculation & measurement & calculation & \\
\hline 1 & 17.67 & 2.88 & 48.56 & 30.89 & 39.95 & 39.59 & 703.09 & 732.40 & 4.17 \\
\hline 2 & 17.92 & 2.58 & 45.32 & 27.40 & 37.89 & 37.46 & 606.75 & 641.58 & 5.74 \\
\hline 3 & 19.12 & 6.84 & 55.63 & 36.50 & 46.11 & 46.17 & 777.02 & 772.26 & -0.61 \\
\hline 4 & 21.98 & 7.32 & 59.38 & 37.39 & 49.53 & 49.80 & 803.78 & 782.10 & -2.70 \\
\hline 5 & 22.46 & 4.42 & 57.32 & 34.86 & 47.89 & 47.52 & 770.51 & 800.57 & 3.90 \\
\hline 6 & 23.05 & 0.54 & 50.05 & 27.00 & 42.51 & 41.93 & 615.55 & 663.10 & 7.72 \\
\hline 7 & 23.62 & 3.43 & 55.91 & 32.29 & 47.09 & 46.64 & 720.17 & 757.56 & 5.19 \\
\hline 8 & 28.23 & 5.19 & 64.63 & 36.39 & 55.05 & 54.59 & 781.72 & 819.27 & 4.80 \\
\hline 9 & 29.01 & 4.85 & 64.36 & 35.35 & 54.69 & 54.55 & 789.43 & 801.04 & 1.47 \\
\hline 10 & 31.16 & 4.65 & 65.98 & 34.82 & 56.81 & 56.28 & 748.90 & 792.36 & 5.80 \\
\hline 11 & 22.58 & 0.94 & 44.32 & 21.74 & 38.30 & 38.05 & 491.62 & 512.41 & 4.23 \\
\hline 12 & 21.00 & 3.20 & 43.71 & 22.71 & 37.35 & 37.60 & 519.39 & 499.36 & -3.86 \\
\hline 13 & 24.53 & 1.84 & 48.46 & 23.93 & 42.03 & 41.60 & 525.11 & 560.21 & 6.69 \\
\hline 14 & 22.70 & 0.63 & 46.89 & 24.19 & 39.88 & 39.75 & 572.47 & 583.01 & 1.84 \\
\hline 15 & 17.21 & 1.16 & 42.96 & 25.75 & 35.81 & 35.35 & 583.91 & 621.52 & 6.44 \\
\hline 16 & 28.66 & 2.51 & 56.42 & 27.76 & 48.34 & 48.42 & 659.85 & 653.29 & -1.00 \\
\hline 17 & 26.11 & 3.87 & 55.35 & 29.24 & 46.59 & 47.27 & 715.39 & 660.04 & -7.74 \\
\hline 18 & 31.71 & 4.59 & 64.43 & 32.72 & 54.67 & 55.42 & 797.05 & 735.77 & -7.69 \\
\hline 19 & 15.67 & 1.13 & 45.22 & 29.55 & 36.54 & 36.28 & 708.85 & 730.24 & 3.02 \\
\hline 20 & 21.82 & 2.44 & 52.37 & 30.55 & 43.08 & 43.38 & 758.67 & 733.92 & -3.26 \\
\hline
\end{tabular}




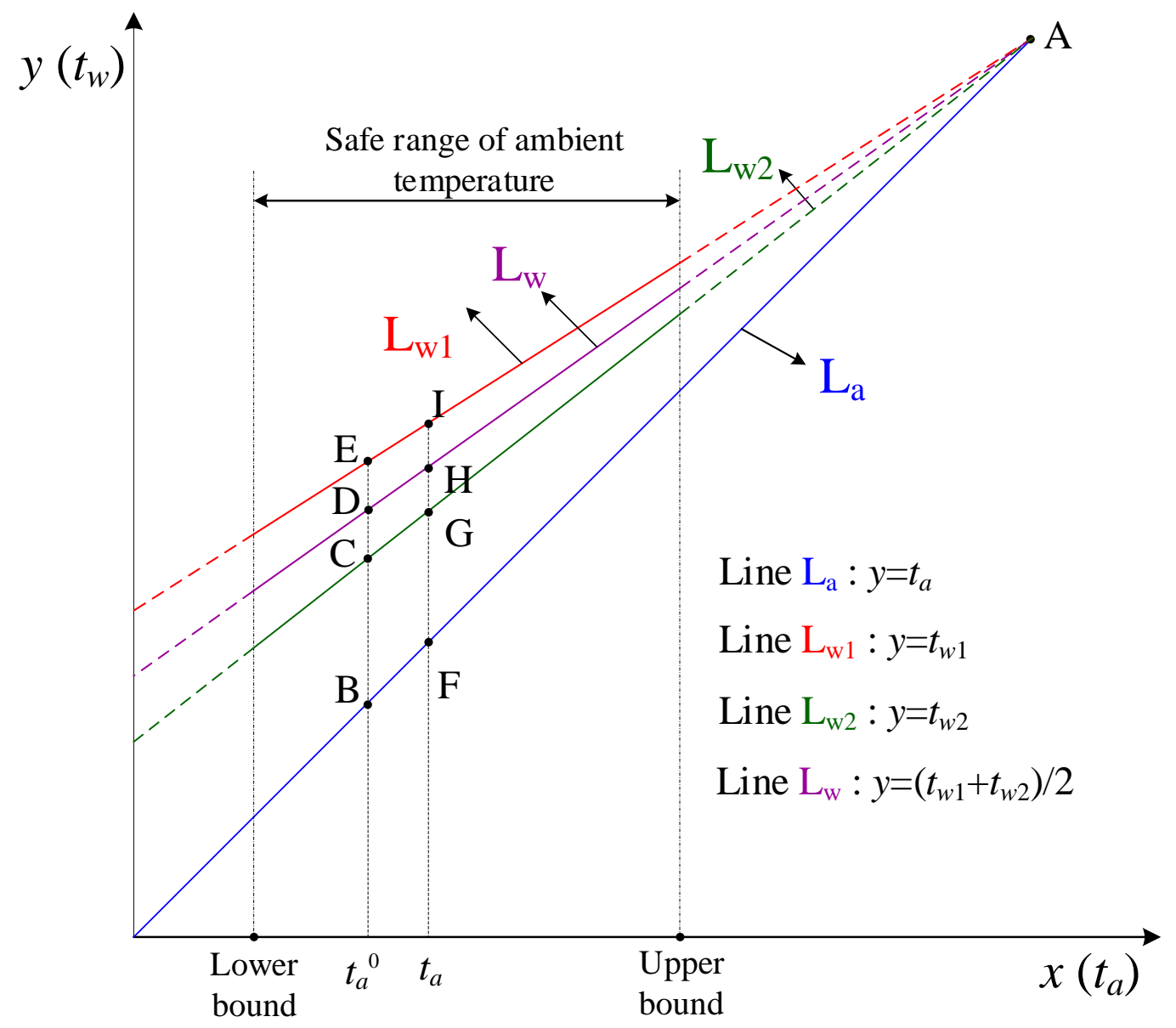

Figure 1. The relationship of cooling water temperature with ambient temperature 


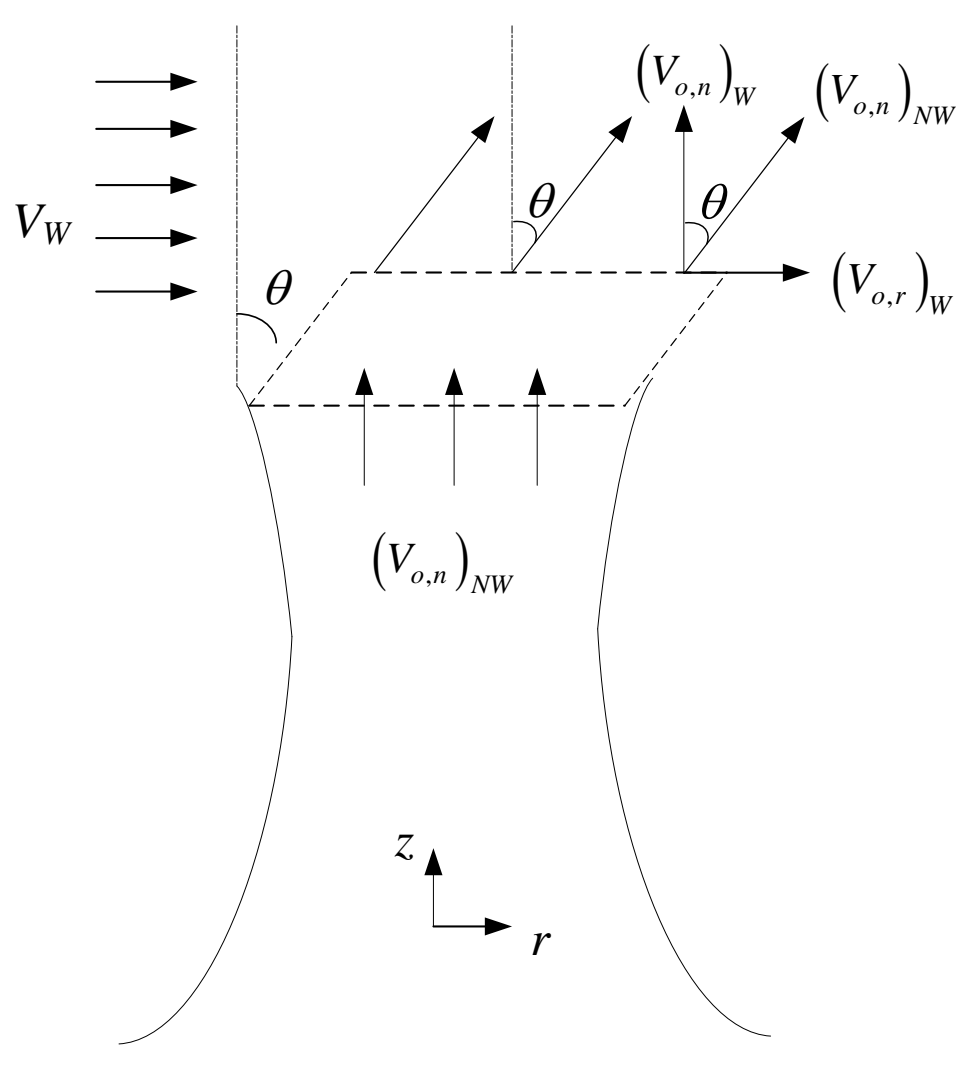

Figure 2. The relationship of outlet air velocity under windless condition with crosswind velocity and the variation of outlet air velocity caused by crosswind 

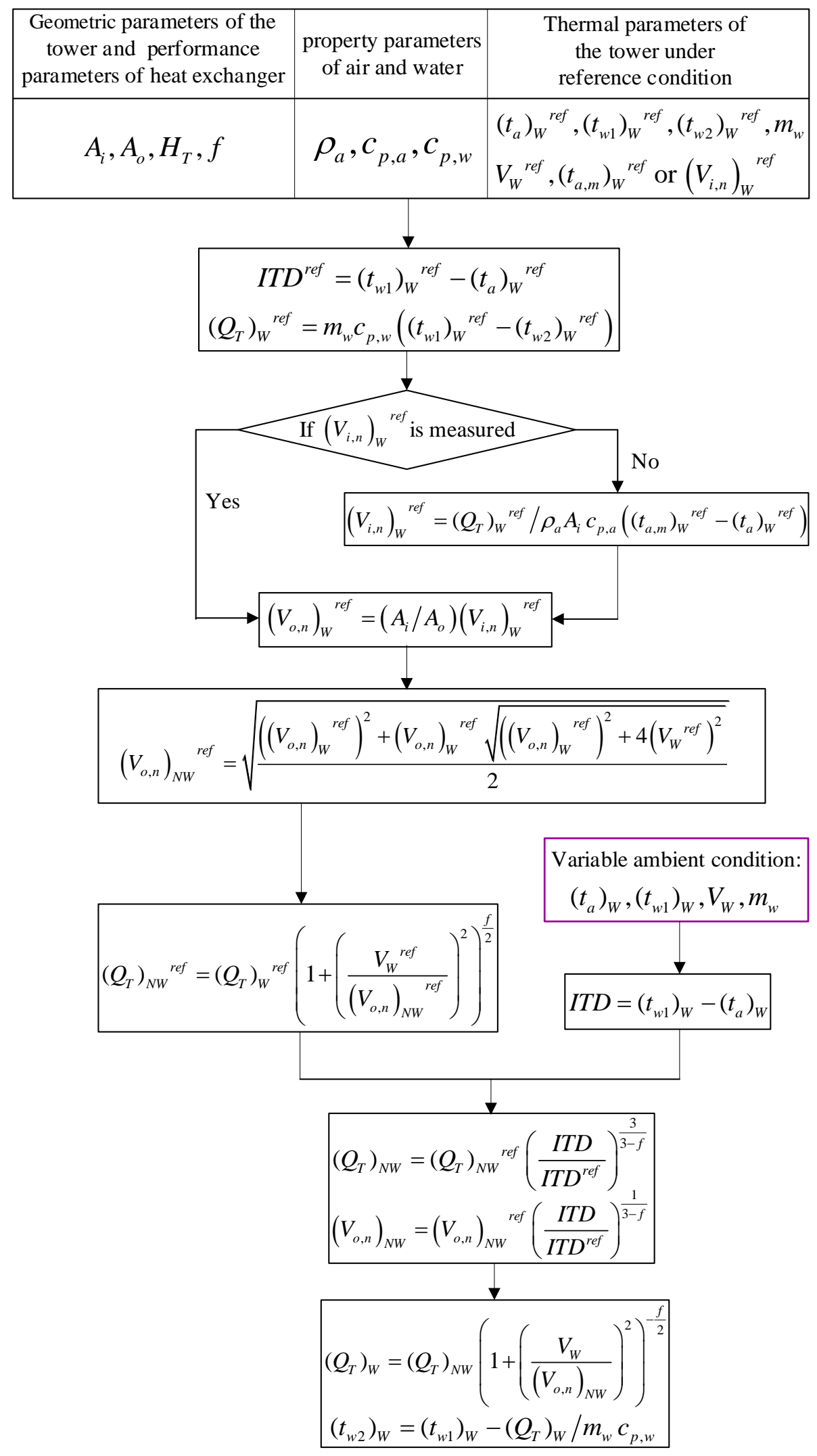

Figure 3. Flow chart of the new theoretical model for thermal calculation of the NDDCT under variable ambient conditions 

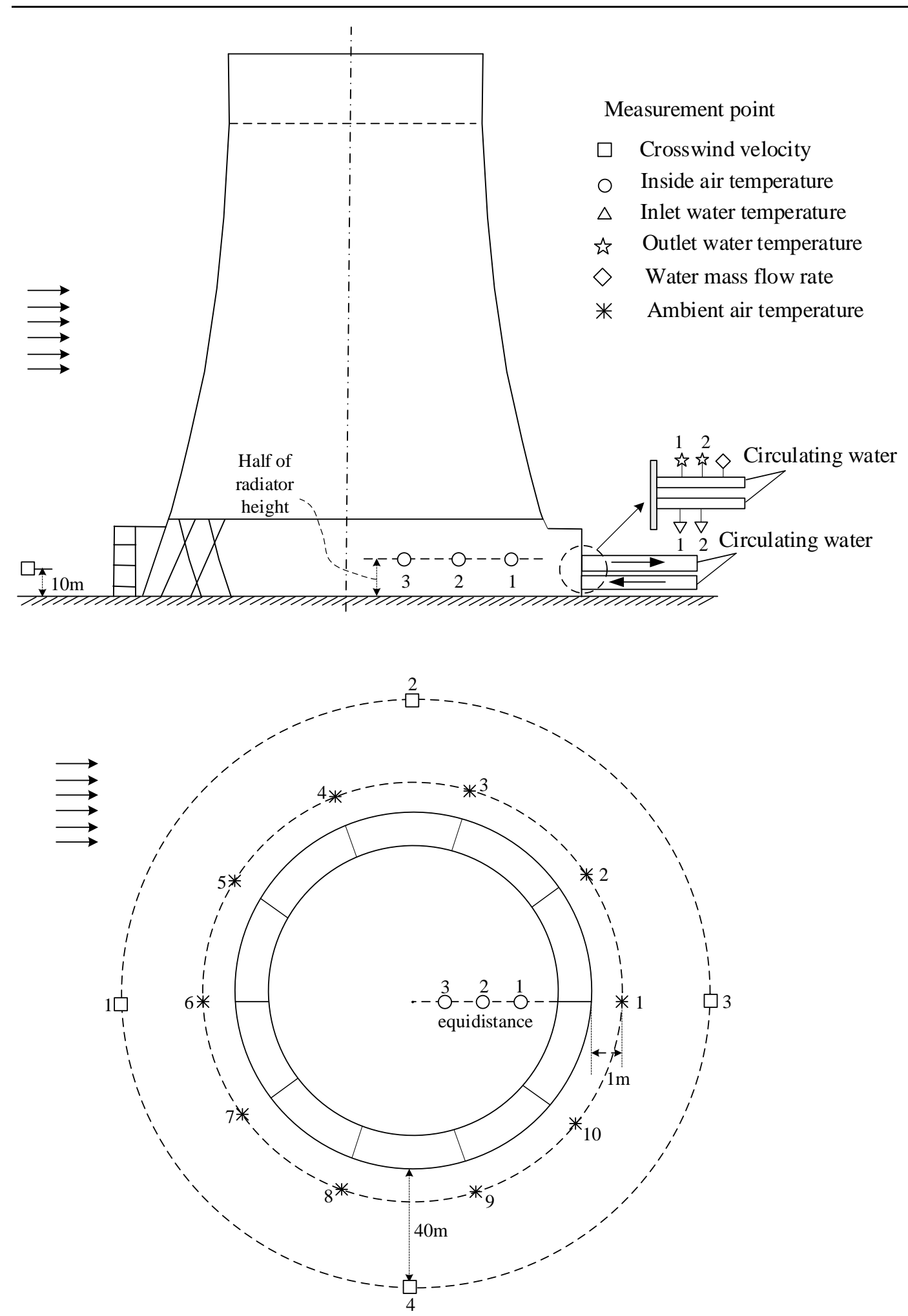

Figure 4. Measurement points arrangement for thermal performance experiment of the NDDCT 


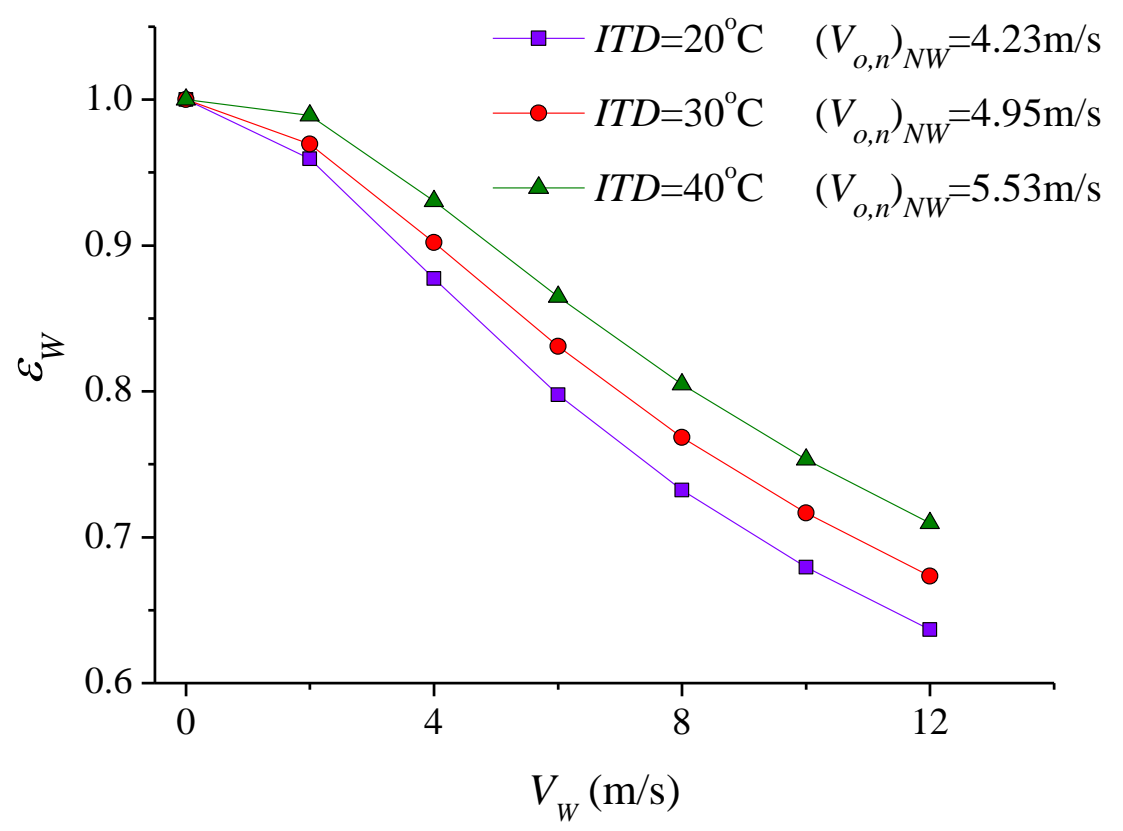

Figure 5. Variations of heat transfer ratio $\varepsilon_{W}$ with crosswind velocity $V_{W}$ under different ITDs 


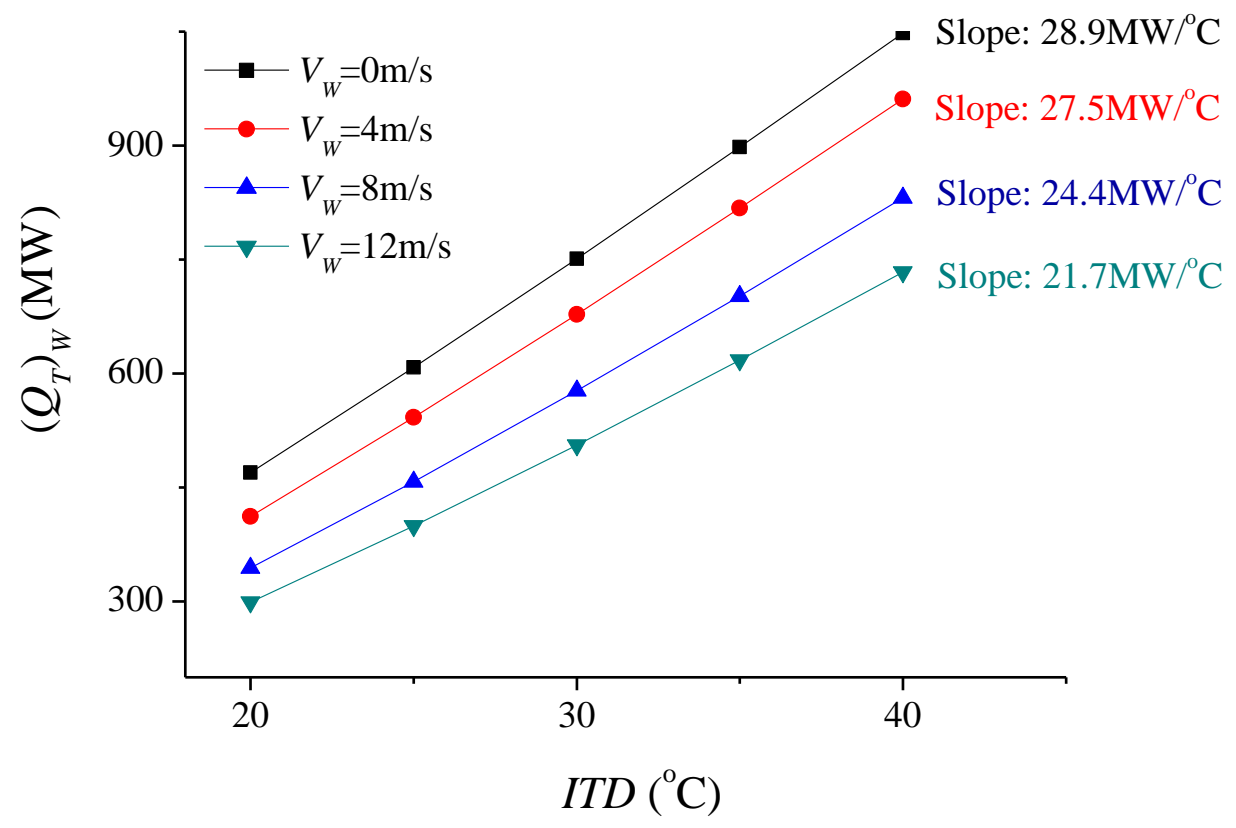

Figure 6. Variations of heat rejection of the tower $\left(Q_{T}\right)_{W}$ with ITD under different crosswind velocities 


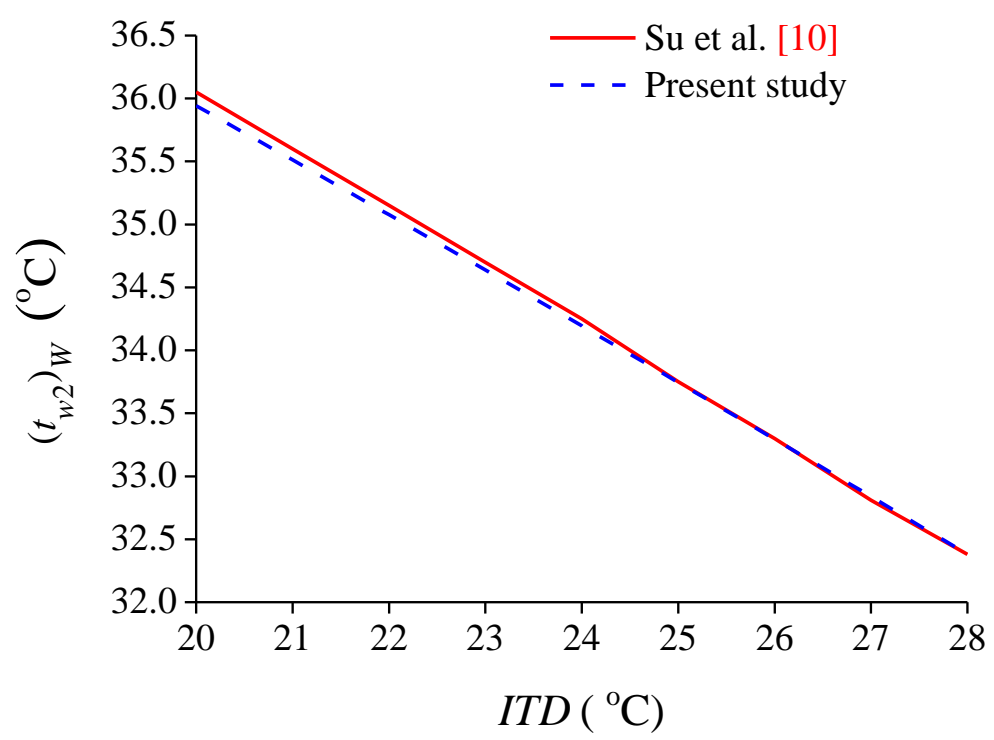

(a)

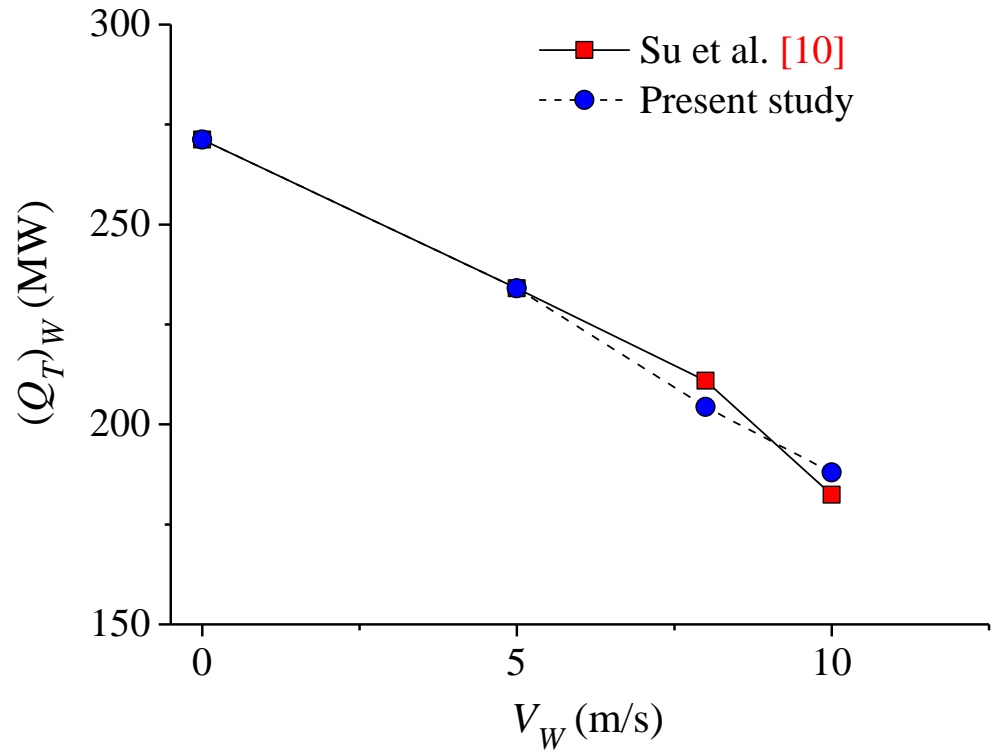

(b)

Figure 7. Comparison of predictions by present theoretical model and simulations in Su et al. [10], (a) in the condition: $V_{W}=0 \mathrm{~m} / \mathrm{s},\left(t_{w 1}\right)_{W}=43^{\circ} \mathrm{C}$; (b) in the condition: $\left(t_{w 1}\right)_{W}=43^{\circ} \mathrm{C},\left(t_{a}\right)_{W}=15^{\circ} \mathrm{C}$ 


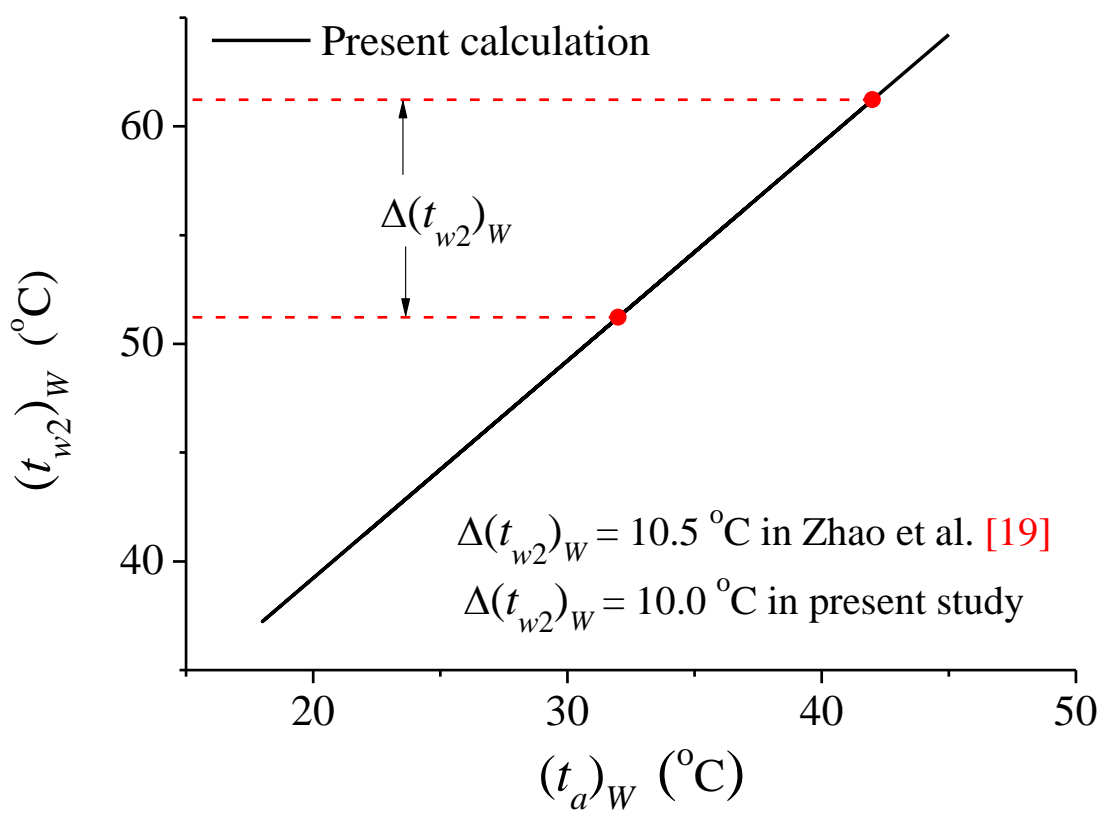

(a)

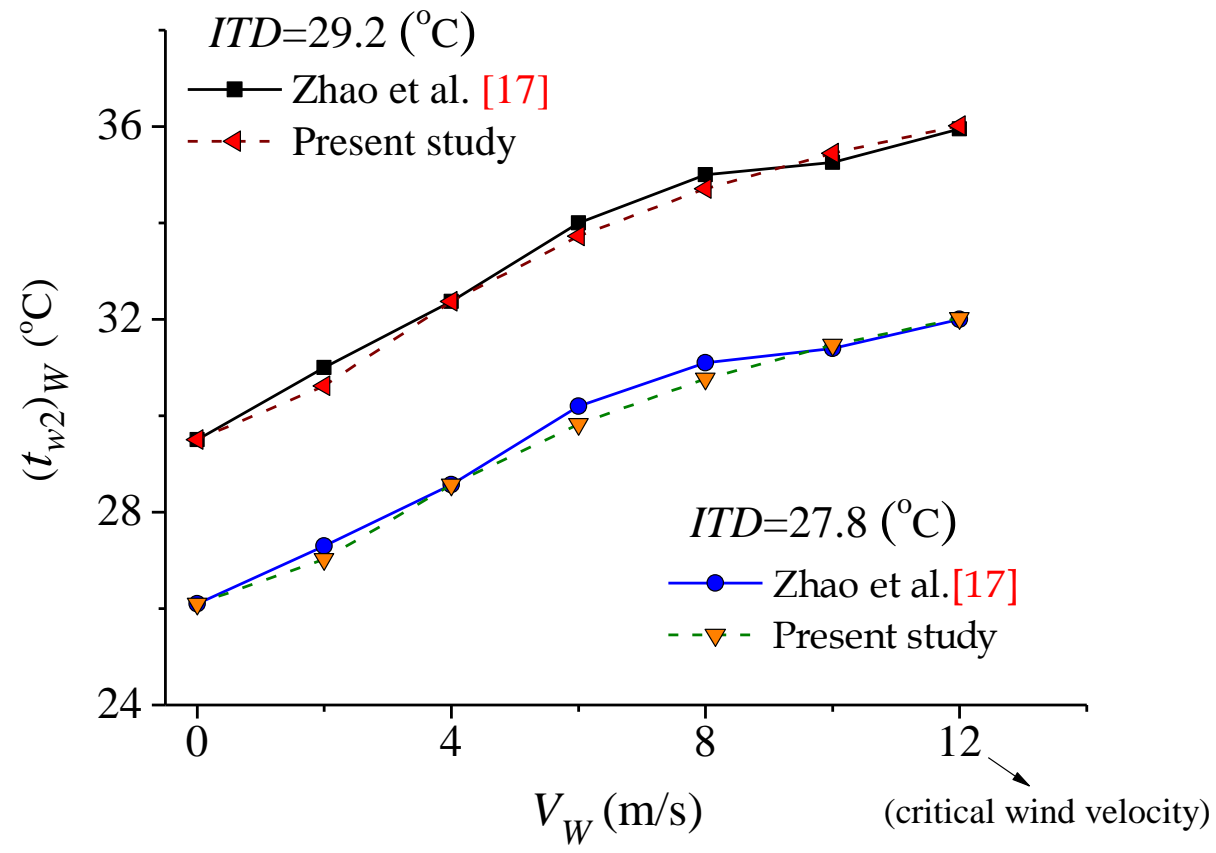

(b)

Figure 8. Comparison of predictions by present theoretical model and results

reported in Zhao et al. [17, 19], (a) in the condition: $\left(Q_{T}\right)_{W}=887.2 \mathrm{MW}, V_{W}=4 \mathrm{~m} / \mathrm{s}$;

(b) in the condition: $I T D=29.2^{\circ} \mathrm{C}\left(\left(t_{w 1}\right)_{W}=43.1^{\circ} \mathrm{C},\left(t_{a}\right)_{W}=13.9^{\circ} \mathrm{C}\right) ; I T D=27.8^{\circ} \mathrm{C}$

$$
\left(\left(t_{w 1}\right)_{W}=39^{\circ} \mathrm{C},\left(t_{a}\right)_{W}=11.2^{\circ} \mathrm{C}\right)
$$

